\title{
Phylogeny of Maleae (Rosaceae) Based on Multiple Chloroplast Regions: Implications to Genera Circumscription
}

\author{
Jiahui Sun $\mathbb{D}^{1},{ }^{1,2}$ Shuo Shi $\mathbb{D}^{1,2,3}$ Jinlu Li, ${ }^{1,4}$ Jing Yu, ${ }^{1}$ Ling Wang, ${ }^{4}$ Xueying Yang, ${ }^{5}$ \\ Ling Guo $\mathbb{1}^{6}{ }^{6}$ and Shiliang Zhou $\mathbb{1}^{1,2}$ \\ ${ }^{1}$ State Key Laboratory of Systematic and Evolutionary Botany, Institute of Botany, Chinese Academy of Sciences, Beijing 100093, China \\ ${ }^{2}$ University of the Chinese Academy of Sciences, Beijing 100043, China \\ ${ }^{3}$ College of Life Science, Hebei Normal University, Shijiazhuang 050024, China \\ ${ }^{4}$ The Department of Landscape Architecture, Northeast Forestry University, Harbin 150040, China \\ ${ }^{5}$ Key Laboratory of Forensic Genetics, Institute of Forensic Science, Ministry of Public Security, Beijing 100038, China \\ ${ }^{6}$ Beijing Botanical Garden, Beijing 100093, China
}

Correspondence should be addressed to Ling Guo; guoling@beijingbg.com and Shiliang Zhou; slzhou@ibcas.ac.cn

Received 21 September 2017; Revised 11 December 2017; Accepted 2 January 2018; Published 19 March 2018

Academic Editor: Fengjie Sun

Copyright (C) 2018 Jiahui Sun et al. This is an open access article distributed under the Creative Commons Attribution License, which permits unrestricted use, distribution, and reproduction in any medium, provided the original work is properly cited.

Maleae consists of economically and ecologically important plants. However, there are considerable disputes on generic circumscription due to the lack of a reliable phylogeny at generic level. In this study, molecular phylogeny of 35 generally accepted genera in Maleae is established using 15 chloroplast regions. Gillenia is the most basal clade of Maleae, followed by Kageneckia + Lindleya, Vauquelinia, and a typical radiation clade, the core Maleae, suggesting that the proposal of four subtribes is reasonable. In the core Maleae including 31 genera, chloroplast gene data support that the four Malus-related genera should better be merged into one genus and the six Sorbus-related genera would be classified into two genera, whereas all Photinia-related genera should be accepted as distinct genera. Although the phylogenetic relationships among the genera in Maleae are much clearer than before, it is still premature to make a formal taxonomic treatment for these genera.

\section{Introduction}

Rosaceae or rose family, consisting of approximately 4,828 species in 91 genera [1], is of great economic and ecological importance. Many species are cultivated for their fruits or as ornamentals. The monophyly of the family is implied by the presence of unique floral structures and strongly supported by $r b c L$ phylogeny [2]. However, the rose family displays a considerable diversity in morphology and anatomy, and it had been generally subdivided into four subfamilies, that is, Rosoideae, Spiraeoideae, Amygdaloideae (incorrectly Prunoideae), and Maloideae. Such a subdivision was recently challenged by molecular phylogenies of matK and trnL-F [3], six nuclear and four chloroplast regions [4], and hundreds of nuclear genes [5]. A formal three-subfamily classification was proposed: Dryadoideae, Rosoideae, and Amygdaloideae (incorrectly Spiraeoideae in [4]). Dryadoideae was separated from Rosoideae, and Spiraeoideae and Maloideae were merged with Amygdaloideae (incorrectly Spiraeoideae).

One of the most striking changes in the new classification is that traditional Maloideae became subtribe Malinae (incorrectly Pyrinae). Here we use tribe Maleae instead of supertribe Pyrodae sensu [4] to include the traditional pome-bearing Maloideae plus Gillenia Moench (=Porteranthus Britton), Kageneckia Ruiz \& Pav., Lindleya Kunth, and Vauquelinia Corrêa ex Bonpl. in traditional Spiraeoideae [4, 6-9].

Maleae consists of about 1,000 species, occurring mostly in the temperate Northern Hemisphere. The tribe includes many well-known fruit crops such as apple (Malus pumila Mill.), pear (Pyrus spp.), loquat (Eriobotrya japonica (Thunb.) Lindl.), and black chokeberry (Aronia melanocarpa (Michx.) 
Elliott), as well as many ornamentals. The core Maleae is characterized by a synapomorphic pome, a type of accessory fruit that does not occur in other Rosaceae plants [10], and a basal chromosome number, $x=17$. With the addition of Gillenia, Kageneckia, Lindleya, and Vauquelinia, the tribe has drupaceous or follicle fruits and $x=9$ (or 15) as well $[2,4,6,9,11-13]$.

The origin of core Maleae $(x=17)$ has long been considered an example of allopolyploidization between the species with $x=9$ in traditional Spiraeoideae and the species with $x=8$ in traditional Amygdaloideae [14-17]. However, recently discovered genomic data suggested an origin via autopolyploidization followed by aneuploidization around 50 million years ago $[18,19]$. In contrast, the allopolyploid nature of core Maleae was confirmed by GBSSI, which had four copies in the core Maleae but only two copies in other groups [6].

Polyploidization affects systematics at both generic and specific levels. It is unlikely to resolve the polytomy of ancestral populations that have just a few closely related species involved in historical speciation and subsequent diversification, owing to the lack of phylogenetically informative signals and incomplete lineage sorting. The merging of several genomes into one species enriches the pool of available genetic combinations and the survival of recombinants is overcome by apomixis. Maleae is one such species-rich tribe of genera but is difficult to classify.

The pome-bearing plants have been generally subdivided into two groups: one with connate endocarps and the other with polypyrenous drupes [10, 20-22]. However, such subdivisions of the core Maleae do not receive support from molecular data. Considerable controversies exist on circumscriptions of genera based on morphology or anatomy [21, 23-37]. Sorbus L. is considered to include both the pinnate-leaved species (Sorbus s.s. and Cormus Spach) and the simple-leaved species (Aria (Pers.) Host, Micromeles Decne., Chamaemespilus Medik., and Torminalis Medik.) [21, 34, 38, 39]. Aronia Medik., Heteromeles M. Roem., Pourthiaea Decne., and Stranvaesia Lindl. are either merged together with Photinia Lindl. or accepted as distinct genera [37, 40, 41]. Varying opinions are also found among Malus Mill., Docyniopsis Koidz., and Eriolobus (DC.) M. Roem., as well as among Pseudocydonia (C. K. Schneid.) C. K. Schneid., Cydonia Mill., and Chaenomeles Lindl. [22, 27, 37]. Lack of consensus treatment among these genera is a result of uncertainty about genetic relationships among all entities (or genera in the narrow sense) and molecular data have been used to reveal their phylogenies. Both chloroplast DNA sequences $[2,4,7,9,42]$ and nuclear DNA sequences ([4, 6-8, 12, 43]; Lo et al., 2012) have been tried, and it is clear that the monophyly of each entity is highly supported; the major unsolved problem is the phylogeny among entities. To elucidate the intricate relationships among these entities (the generally recognized genera in the narrow sense within Maleae), we sampled representative species for each of them, including the occasionally accepted genera and subgenera, and constructed their phylogeny using 15 chloroplast regions. Our results are expected to be helpful for the correct circumscription of genera in Maleae.

\section{Materials and Methods}

2.1. Taxon Sampling. A total of 41 species were examined: 35 species representing all generally recognized genera of Maleae and five species representing other major lineages of Amygdaloideae and Rosa rugosa Thunb. as an outgroup (Table 1). All samples were collected under appropriate permits: Herbarium, Institute of Botany, CAS; Beijing Botanical Garden, CAS; Kunming Botanical Garden, CAS; and Xishuangbanna Tropical Botanical Garden, CAS; and other places listed in Table 1.

2.2. DNA Extraction, Amplification, and Sequencing. Total genomic DNA was extracted using the mCTAB method [44] and purified using the Wizard DNA Clean-Up System (A7280, Promega Corporation, Madison, WI). Fifteen chloroplast regions, that is, atpB-rbcL, matK, $n d h F, p e t A-p s b J$, psbA-trnH, psbM-trnD, rbcL, rpl16, rpl20-rps12, rps16, trnC$y c f 6, \operatorname{trnH}-r p l 2, \operatorname{trnL}-\operatorname{trnF}, \operatorname{trnS}-\operatorname{trn} G$, and $y c f 1$, were used in this study. Fourteen primer pairs published in Dong et al. $[45,46]$ were synthesized by Sangon Biotech (Shanghai) Co. Ltd. (Beijing, China) and used to amplify and sequence these regions (Table 2). Sequences of rps16 were downloaded from GenBank. The polymerase chain reaction (PCR) amplifications were carried out in a mixture volume of $20 \mu \mathrm{L}$, containing 1x Taq buffer $(1 \mathrm{~mol} / \mathrm{L} \mathrm{KCl} ; 20 \mathrm{mmol}$ Tris- $\mathrm{HCl}$ pH 9.0; $1 \%$ Triton X-100), $2.0 \mu \mathrm{L}$ dNTPs $(2 \mathrm{mmol} / \mathrm{L}), 1.0 \mu \mathrm{L}$ each of the primers $(5 \mu \mathrm{mol} / \mathrm{L}), 20 \mathrm{ng}$ of genomic DNA, and 1 unit of Taq polymerase. PCR was conducted using a C1000 Thermal Cycler (Bio-Rad Laboratories, Hercules, CA, USA). The program started at $94^{\circ} \mathrm{C}$ for $3 \mathrm{~min}$, followed by 35 cycles at $94^{\circ} \mathrm{C}$ for $30 \mathrm{~s}, 50^{\circ} \mathrm{C}$ for $30 \mathrm{~s}$, and $72^{\circ} \mathrm{C}$ for $2 \mathrm{~min}$, and ended at $72^{\circ} \mathrm{C}$ for $5 \mathrm{~min}$. The PCR products were purified with an equal mixture of $40 \%$ PEG 8000 and $5 \mathrm{~mol} / \mathrm{L} \mathrm{NaCl}$, followed by a washing step with $80 \%$ ethanol. The PCR products were then Sanger sequenced for both strands on an ABI 3730xl DNA Analyzer using BigDye Terminator cycle sequencing kit v3.1 (Applied Biosystems, Foster City, CAS, USA) following the manufacturer's instructions.

2.3. Sequence Data Preparation and Evaluation. The newly generated sequences were checked and assembled using Sequencer 4.7 (Gene codes Corporation, Ann Arbor, Michigan, USA). The resulting sequences (Supplementary Table S2) were combined with the published sequences of Maleae species downloaded from GenBank (Supplementary Table S1), aligned with Clustal X [47, 48], and then manually adjusted with Se-Al 2.0 [49]. Each individual gene dataset was then subjected to several rounds of phylogenetic evaluations to select reliable sequences. Sequences that were misidentified or exhibited large amounts of missing data were excluded from the datasets. To predict the phylogenetic performance of individual gene partitions, the variability of genes was parameterized by DnaSP 5.0 [50] and PAUP 4.0b10 [51] using nucleotide diversity, the number of polymorphic sites, and so forth. Prior to concatenating the dataset of each marker, incongruence length difference (ILD) tests were performed on all 15 datasets. The datasets were finally concatenated 
TABLE 1: Representative species of Maleae, other major lineages of Amygdaloideae, and an outgroup used in this study, together with sample vouchers and sampling localities.

\begin{tabular}{|c|c|c|}
\hline Taxon & Voucher & Locality \\
\hline Amelanchier arborea (F. Michx.) Fernald & S. L. Zhou BOP022147 & Herbarium, Institute of Botany, CAS (PE) \\
\hline Aria nivea Host & S. L. Zhou BOP022174 & Herbarium, Institute of Botany, CAS (PE) \\
\hline Aronia melanocarpa (Michx.) Elliott & S. L. Zhou BOP022150 & Herbarium, Institute of Botany, CAS (PE) \\
\hline Chaenomeles speciosa (Sweet) Nakai & S. L. Zhou BOP010027 & Beijing Botanical Garden, CAS \\
\hline Chamaemeles coriacea Lindl. & K. R. Roberson 4775 & Illinois Natural History Survey Herbarium (ILLS) \\
\hline Chamaemespilus alpina (Mill.) K. R. Robertson \& J. B. Phipps & K. R. Roberson 5276 & Illinois Natural History Survey Herbarium (ILLS) \\
\hline Cormus domestica (L.) Spach & S. L. Zhou BOP022163 & Herbarium, Institute of Botany, CAS (PE) \\
\hline Cotoneaster multiflorus Bunge & S. L. Zhou BOP010016 & Beijing Botanical Garden, CAS \\
\hline Crataegus kansuensis E. H. Wilson & S. L. Zhou BOP010010 & Beijing Botanical Garden, CAS \\
\hline Cydonia oblonga Mill. & S. L. Zhou BOP010020 & Beijing Botanical Garden, CAS \\
\hline Dichotomanthes tristaniicarpa Kurz & S. L. Zhou BOP027700 & Kunming Botanical Garden, CAS \\
\hline Docynia delavayi (Franch.) C. K. Schneid. & S. L. Zhou BOP027738 & Xishuangbanna Tropical Botanical Garden, CAS \\
\hline Docyniopsis tschonoskii (Maxim.) Koidz. & S. L. Zhou BOP022164 & Herbarium, Institute of Botany, CAS (PE) \\
\hline Eriobotrya japonica (Thunb.) Lindl. & S. L. Zhou BOP003044 & Beijing Botanical Garden, CAS \\
\hline Eriolobus kansuensis (Batalin) C. K. Schneid. & S. L. Zhou BOP011038 & Huludao, Liaoning, CHN \\
\hline Gillenia trifoliata (L.) Moench & S. L. Zhou BOP022159 & Herbarium, Institute of Botany, CAS (PE) \\
\hline Heteromeles arbutifolia (Dryand.) M. Roem. & S. L. Zhou BOP022160 & Herbarium, Institute of Botany, CAS (PE) \\
\hline Kageneckia crataegifolia Lindl. & S. L. Zhou BOP022176 & Herbarium, Institute of Botany, CAS (PE) \\
\hline Lindleyella schiedeana (Schltdl.) Rydb. & S. L. Zhou BOP022161 & Herbarium, Institute of Botany, CAS (PE) \\
\hline Malacomeles denticulata (Kunth) G. N. Jones & S. L. Zhou BOP022179 & Herbarium, Institute of Botany, CAS (PE) \\
\hline Malus baccata (L.) Borkh. & S. L. Zhou BOP016421 & Beijing Botanical Garden, CAS \\
\hline Mespilus germanica L. & S. L. Zhou BOP022165 & Herbarium, Institute of Botany, CAS (PE) \\
\hline Micromeles folgneri C. K. Schneid. & S. L. Zhou BOP017025 & Harbin, Heilongjiang, CHN \\
\hline Osteomeles schwerinae C. K. Schneid. & S. L. Zhou BOP027697 & Kunming Botanical Garden, CAS \\
\hline Peraphyllum ramosissimum Nutt. ex Torr. \& A. Gray & S. L. Zhou BOP022168 & Herbarium, Institute of Botany, CAS (PE) \\
\hline Photinia serratifolia (Desf.) Kalkman & S. L. Zhou BOP027633 & Beijing Botanical Garden, CAS \\
\hline Pourthiaea arguta var. salicifolia (Decne.) Hook. f. & S. L. Zhou BOP022178 & Herbarium, Institute of Botany, CAS (PE) \\
\hline Pseudocydonia sinensis (Dum. Cours.) C. K. Schneid. & S. L. Zhou BOP010349 & Beijing Botanical Garden, CAS \\
\hline Pyracantha fortuneana (Maxim.) H. L. Li & S. L. Zhou BOP003043 & Beijing Botanical Garden, CAS \\
\hline Pyrus bretschneideri Rehder & S. L. Zhou BOP010065 & Beijing Botanical Garden, CAS \\
\hline Rhaphiolepis indica (L.) Lindl. & S. L. Zhou BOP016354 & Kunming Botanical Garden, CAS \\
\hline Sorbus aucuparia L. & S. L. Zhou BOP016569 & Harbin, Heilongjiang, CHN \\
\hline Stranvaesia davidiana Decne. & S. L. Zhou BOP027698 & Kunming Botanical Garden, CAS \\
\hline Torminalis clusii (M.Roem.) K. R. Robertson \& J. B. Phipps & K. R. Roberson 5275 & Illinois Natural History Survey Herbarium (ILLS) \\
\hline Vauquelinia corymbosa Corrêa ex Humb. \& Bonpl. & S. L. Zhou BOP022177 & Herbarium, Institute of Botany, CAS (PE) \\
\hline \multicolumn{3}{|l|}{ Other lineages } \\
\hline Physocarpus amurensis (Maxim.) Maxim. & S. L. Zhou BOP010043 & Beijing Botanical Garden, CAS \\
\hline Prinsepia sinensis (Oliv.) Oliv. ex Bean & S. L. Zhou BOP010133 & Beijing Botanical Garden, CAS \\
\hline Rhodotypos scandens (Thunb.) Makino & S. L. Zhou BOP010022 & Beijing Botanical Garden, CAS \\
\hline Sorbaria sorbifolia (L.) A. Braun & S. L. Zhou BOP016568 & Beijing Botanical Garden, CAS \\
\hline Spiraea pubescens Turcz. & S. L. Zhou BOP010042 & Beijing Botanical Garden, CAS \\
\hline \multicolumn{3}{|l|}{ Outgroup } \\
\hline Rosa rugosa Thunb. & S. L. Zhou BOP010536 & Beijing Botanical Garden, CAS \\
\hline
\end{tabular}

into one final data matrix using SequenceMatrix [52] for phylogenetic analyses.

2.4. Phylogenetic Analysis. Phylogenetic analyses were performed on single gene datasets and the concatenated dataset, using PAUP 4.0b10 [51] for maximum parsimony (MP), RAxML v.8.1.24 [53] for maximum likelihood (ML), and MrBayes 3.2.2 [54] for Bayesian inference (BI). The MP analysis used a heuristic search that treats all characters as equally weighted and unordered, obtaining the starting trees 
TABLE 2: Primers used to amplify and sequence 15 regions of chloroplast genome of Rosaceae.

\begin{tabular}{lccc}
\hline Gene regions & Forward primer $\left(5^{\prime}-3^{\prime}\right)$ & Reverse primer $\left(5^{\prime}-3^{\prime}\right)$ & Reference \\
\hline$a t p B-r b c L$ & TTTCCTAATAATTGCTGTACC & ACAGTTGTCCATGTACCAGTAG & Dong et al., 2013 [45] \\
$m a t K$ & TCTAGCACACGAAAGTCGAAGT & CGATCTATTCATTCAATATTTC & Dong et al., 2013 [45] \\
$n d h F$ & ACACCAACGCCATTCGTAATGCCATC & AAGATGAAATTCTTAATGATAGTTGG & Dong et al., 2013 [45] \\
$p e t A-p s b J$ & CTAATGTGGGTGGATTTGGTCA & ATGGCCGATACTACTGGAAGG & This study \\
$p s b$ - $r n H$ & GAACCCGCGCATGGTGGATTCAC & TGGCTCCCTATTCAGTGCTATGC & This study \\
$p s b M-t r n D$ & GTTTTTACGTATATTATAAGTA & GTTCAAATCCAGCTCGGCCCA & This study \\
$r b c L$ & ATGTCACCACAAACAGAGACTAAAGC & TTCCATACTTCACAAGCAGCAGCTAG & Dong et al., 2013 [45] \\
$r p l 16$ & TCCCGAAATAATGAATTGAGTTCG & TCAGAGAAGGTAGGGTTCCCCT & Dong et al., 2013 [45] \\
$r p l 20-r p s 12$ & ATGATCTCATTGGAAATCATATAAAG & AGGGTAATGATCCATCAACCGGC & Dong et al., 2013 [45] \\
$r p s 16$ & GTGGTAGAAAGCAACGTGCGACTT & TCGGGATCGAACATCAATTGCAAC & Oxelman et al., 1997 [85] \\
$t r n C-y c f 6$ & GGCGGCATGGCCGAGTGGTAAGGC & TCCACTTCTTCCCCATACTACGA & Dong et al., 2013 [45] \\
$t r n H-r p l 2$ & AGCCAACACTTAGATCCGGCTCTAC & GATTTGTGAATCCACCATGCGCG & Dong et al., 2013 [45] \\
$t r n L-t r n F$ & GTTCAAGTCCCTCTATCCCCA & GATTTTCAAGAACGGGAATCTTA & Dong et al., 2013 [45] \\
$t r n S-t r n G$ & AAACTCTTCGTTTACACAGTAGTGA & CTTTTACCACTAAACTATACCCGC & Dong et al., 2013 [45] \\
$y c f 1$ & TCTCGACGAAAATCAGATTGTTGTGAAT & ATACATGTCAAAGTGATGGAAAA & Dong et al., 2015 [46] \\
\hline
\end{tabular}

TABLE 3: Variability of 15 chloroplast regions among species in Maleae and the maximum parsimony tree scores of all taxa.

\begin{tabular}{lccccccccccc}
\hline Gene regions & $N^{*}$ & $\mathrm{La}$ & $\mathrm{Sc}$ & $\mathrm{S}$ & $\mathrm{Is}$ & $\mathrm{NH}$ & $\pi$ & $k$ & $L^{*}$ & $\mathrm{CI}^{*}$ & $\mathrm{RI}^{*}$ \\
\hline atpB-rbcL & 39 & 796 & 659 & 33 & 9 & 25 & 0.00422 & 4.15 & 177 & 0.921 & 0.781 \\
matK & 41 & 2045 & 1761 & 167 & 47 & 32 & 0.00879 & 8.17 & 663 & 0.741 & 0.538 \\
ndhF & 39 & 1973 & 1821 & 148 & 38 & 29 & 0.00937 & 7.5 & 694 & 0.745 & 0.567 \\
petA-psbJ & 34 & 1370 & 1072 & 155 & 36 & 27 & 0.01046 & 11.31 & 554 & 0.791 & 0.629 \\
psbA-trnH & 37 & 283 & 222 & 34 & 10 & 15 & 0.02547 & 12.01 & 196 & 0.789 & 0.436 \\
psbM-trnD & 34 & 1503 & 1225 & 126 & 33 & 27 & 0.00901 & 8.38 & 589 & 0.81 & 0.666 \\
rbcL & 38 & 1353 & 1293 & 60 & 25 & 25 & 0.00539 & 4.43 & 296 & 0.547 & 0.442 \\
rpl16 & 40 & 1178 & 940 & 124 & 31 & 32 & 0.00804 & 10.53 & 463 & 0.689 & 0.518 \\
rpl20-rps12 & 37 & 743 & 677 & 42 & 15 & 30 & 0.00710 & 5.65 & 230 & 0.752 & 0.617 \\
rps16 & 39 & 964 & 772 & 84 & 22 & 28 & 0.00999 & 8.71 & 378 & 0.746 & 0.639 \\
trnC-ycf6 & 36 & 1032 & 810 & 90 & 30 & 28 & 0.01084 & 8.72 & 525 & 0.785 & 0.616 \\
trnH-rpl2 & 36 & 205 & 189 & 11 & 5 & 5 & 0.00391 & 5.37 & 196 & 0.789 & 0.436 \\
trnL-trnF & 41 & 1088 & 944 & 90 & 24 & 26 & 0.00783 & 8.27 & 420 & 0.757 & 0.612 \\
trnS-trnG & 36 & 895 & 661 & 102 & 20 & 27 & 0.01011 & 11.4 & 470 & 0.781 & 0.528 \\
ycf1 & 34 & 866 & 742 & 88 & 21 & 28 & 0.01210 & 10.16 & 489 & 0.765 & 0.595 \\
\hline
\end{tabular}

$N$, number of species; La, aligned length; Sc, sites considered; $S$, number of polymorphic sites, excluding sites with missing data; Is, parsimony-informative site; $\mathrm{NH}$, number of haplotypes; $\pi$, nucleotide diversity; $k$, average number of nucleotide differences; $L$, the tree length; CI, consistency index; RI, retention index. ${ }^{*}$ Including all taxa.

by stepwise addition, random stepwise addition of 100 replicates, TBR, and MulTrees enabled. Branch support for MP trees was assessed with 1,000 bootstrap replicates and all trees were saved at each replicate. ML analysis was performed with 1,000 nonparametric bootstrap replicates (BP). The suitable substitution model $(\mathrm{GTR}+\mathrm{I}+\mathrm{G})$ for BI analysis was inferred by using ModelTest version 3.7 [55] under the Akaike information criterion. Default settings were used for the MrBayes run, and $2 \times$ four chains were run for ten million generations, sampled every 1,000 generations. Posterior probabilities (PP) were calculated from the majority consensus of all of the sampled trees when the standard deviation of the split frequencies (SDSF) permanently fell below 0.01 , and the trees sampled during the burn-in phase were discarded.

\section{Results}

3.1. Sequence Variability within Maleae. The ILD tests did not suggest serious conflicts between datasets of the 15 chloroplast regions $(p=0.11)$. The variability of the 15 examined DNA regions within Maleae are given in Table 3, together with the MP tree scores of all taxa. The longest DNA region was $\operatorname{matK}(\mathrm{La}=2045)$, and the shortest was trnH-rpl2 $(\mathrm{La}=205)$. Of the 15 chloroplast regions, $p s b A-\operatorname{trn} H$ was the most variable fragment with a $\pi$ (nucleotide diversity) value of 0.02547, whereas trnH-rpl2 was the least variable fragment with a $\pi$ value of 0.00391 . The $p s b A-\operatorname{trn} H$, petA-psbJ, $y c f 1$, $\operatorname{trnS}$ - $\operatorname{trn} G$, and $\operatorname{trn} C-y c f 6$ gene regions were more variable $(\pi>0.010)$ than other genes. 
The concatenated data matrix of the 41 taxa reached an aligned length of 17,554 bp with 1,266 parsimony-informative characters. MP searches yielded one best tree with a consistency index (CI) of 0.779 , a retention index (RI) of 0.637 , and a tree length of 5,974 .

\subsection{Phylogenetic Relationships of the Basal Maleae. Poly-} tomies were observed in all the 15 best trees based on each chloroplast region. However, the tree topologies were similar; we thus concatenated them to build best resolved phylogenetic trees using MP, ML, and BI methods. The consensus trees from the MP, ML, and BI analyses showed substantially identical topologies and the monophyly of Maleae was recovered (Figure 1). A long branch leads to the crown taxa of Maleae, including Gillenia, Lindleya, Kageneckia, and Vauquelinia (Figure 1(A)), and this branch is strongly supported (Figure $1(\mathrm{~B}))(\mathrm{PB}=100, \mathrm{BP}=100$, $\mathrm{PP}=1)$.

An earliest and remarkable divergence of Gillenia is clearly indicated in Figure 1. Lindleya and Kageneckia form a monophyletic clade and they diverged slightly earlier than Vauquelinia. The divergence among Lindleya + Kageneckia, Vauquelinia, and the core Maleae happened within a very short span of time, as indicated by the very short branches. All the three branches are well supported. The basal branching pattern of Maleae may serve as the foundation of subtribal division within the tribe if necessary.

3.3. Phylogenetic Relationships within the Core Maleae. The monophyly of the core Maleae is clearly indicated (Figure $1(\mathrm{~A})$ ) and well supported (Figure 1(B)). The genera in the core Maleae seem to be from the second radiation event. Nevertheless, three multigenus clades within the core Maleae are recognizable. Clade I consists of Amelanchier Medik., Crataegus L., Cydonia Mill., Malacomeles (Decne.) Decne., Mespilus L., and Peraphyllum Nutt. and is well supported $(\mathrm{PB}=95, \mathrm{BP}=90, \mathrm{PP}=1)$. A very close relationship between Crataegus and Mespilus is indicated. Clade II (PB = $65, \mathrm{BP}=79, \mathrm{PP}=1$ ) consists of four Photinia-related, three Sorbus-related, and three distinct entities. There are four pairs of genera in this clade but only two of them are highly supported $(\mathrm{PB}=100, \mathrm{BP}=100, \mathrm{PP}=1)$, namely, Eriobotrya Lindl. versus Rhaphiolepis Lindl. and Micromeles Decne. versus Sorbus L. Stranvaesia Lindl. was closer to Cotoneaster Mecik. rather than to Photinia Lindl. Clade III consists of four Malus-related, one Photinia-related, three Sorbus-related, and five distinct entities and is weakly supported $(\mathrm{PB}=50$, $\mathrm{BP}=67, \mathrm{PP}=0.91)$. Very close relationships were revealed between Malus-related Docyniopsis Koidz. and Malus Mill. $(\mathrm{PB}=100, \mathrm{BP}=100, \mathrm{PP}=1)$ and among the Sorbus-related Aria (Pers.) Host, Chamaemespilus Medik., and Torminalis Medik. $(\mathrm{PB}=72, \mathrm{BP}=94, \mathrm{PP}=1)$. Docynia Decne. and Eriolobus (DC.) Roem. also fall in the same clade as Docyniopsis and Malus, but the clade is only weakly supported $(\mathrm{PB}=56, \mathrm{BP}=67, \mathrm{PP}=1)$. Chaenomeles Lindl. is related to Pseudocydonia (C. K. Schneid.) C. K. Schneid. (BP = 52, $\mathrm{PP}=1)$.

\section{Discussion}

4.1. Taxa and Gene Sampling Strategies. It is often a challenge to reconstruct the phylogeny of taxa from recent radiation events due to unclear relationships among subdivisions and low resolution of markers. Maleae is such a taxon and that is why early studies failed to establish solid phylogenetic relationships among its subdivisions. In "A checklist of the subfamily Maloideae (Rosaceae)" [21], only 23 genera were accepted. Six Sorbus-related entities, that is, Aria, Chamaemespilus, Cormus, Micromeles, Sorbus, and Torminalis, were proposed to be merged. To test the distinctness of these taxa, we included all of them in this study. Malus-related and Photiniarelated entities have similar taxonomic problems. Inclusion of representative species from other lineages of Amygdaloideae was to test the monophyly of Maleae. Considering that the monophyly of the genera in the narrowest sense has been well verified, 35 entities with one representative species each were sampled for being the most inclusive and economically affordable.

Sampling chloroplast regions as molecular markers for Maleae is another challenge. The tribe was found to be quite young and the core Maleae was even younger. Chloroplast markers have showed very low resolutions in previous studies $[2,4,7,9,42]$. Therefore, the most variable regions suggested by Dong et al. [56] were used together with the four conventional DNA barcodes, matK, psbA-trnH, rbcL, and $y c f 1$ [46]. By doing so, the major groups in Maleae were well resolved.

4.2. Phylogenetic Relationships among Major Groups of Maleae. The phylogeny (Figure 1) strongly suggests inclusion of Gillenia, Kageneckia, Lindleya, and Vauquelinia in Maleae (incorrectly Pyrodae in [7] and in [4]). Gillenia seemed to diverge slightly early, and Kageneckia + Lindleya, Vauquelinia, and the core Maleae are quite probably from the first radiation event. Although the inclusion of Kageneckia, Lindleya, and Vauquelinia into Maleae seems disagreeable with respect to fruit types, their basal chromosome number ( $x=15$ or 17) suggests that they had probably experienced similar speciation events. They bridge the gap between the core Maleae and true spiraeoid Gillenia. The inclusion of Gillenia in Maleae verifies that the core Maleae is from spiraeoid members within the tribe or other tribes in Amygdaloideae. Unfortunately, transcriptome data of nuclear genes did not provide more information for the issue of origin of the core Maleae because Figure 1 is substantially similar to the tree topologies based on transcriptome data in [5]. Given that Gillenia is the only diploid member in Maleae, the ancestor of Gillenia or its close relatives must be the maternal parent of the extant Maleae.

4.3. Phylogenetic Relationships within the Core Maleae. The core Maleae is a natural group with several synapomorphic characters, such as syncarpous ovaries, epigynous flowers, and fleshy fruits derived from the hypanthial ovary [57-59]. It could be better classified as subtribe Malinae (incorrectly Pyrinae) if necessary. The Malinae diverged into genera by radiation which is the second radiation event in Malese. The 


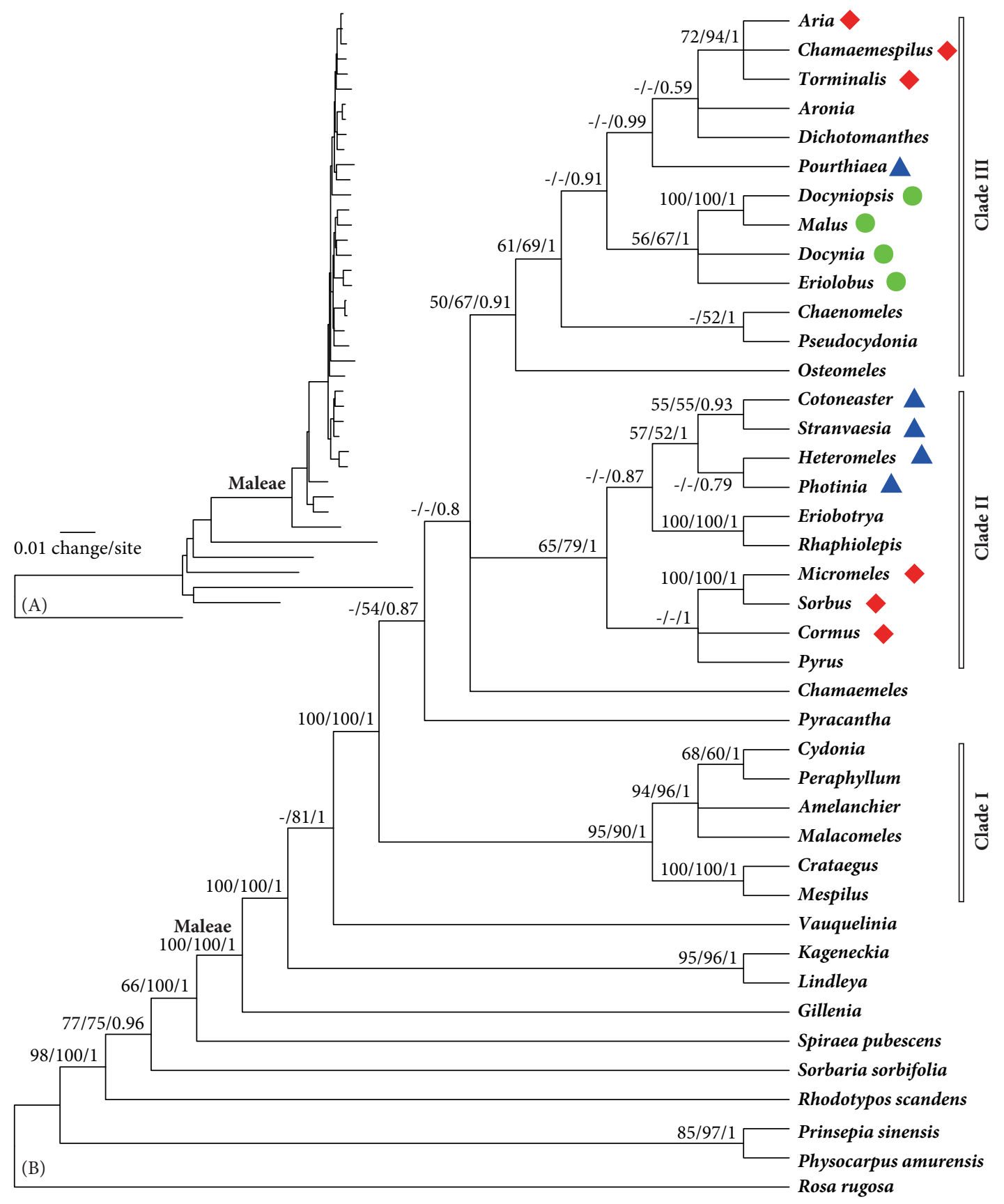

Sorbus-related

Malus-related

Photinia-related

FIGURE 1: Phylogenetic relationships of Maleae based on a concatenated dataset of 15 chloroplast gene regions. (A) Bayesian phylogram with branch lengths. (B) 50\% majority-rule Bayesian consensus tree with bootstrap supports. Values beside the branches are the bootstrap percentages from maximum parsimony analysis, maximum likelihood analysis, and Bayesian posterior probabilities. “-” indicates a branch collapse in the maximum parsimony and maximum likelihood trees.

genera are so closely related that it is unnecessary to subdivide this subtribe further.

4.3.1. Generic Pairs and Their Taxonomic Status. There are four generic pairs, for which the taxonomic status needs to be clarified. Firstly, a close genetic relationship between Crataegus and Mespilus has been revealed by Lo and Donoghue [9] in detail, which is confirmed here again. If Mespilus were to be accepted as a distinct genus, Crataegus would become a paraphyletic group. Although Mespilus was merged with 
Crataegus, its distinction was still recognized by giving it the taxonomic rank of section in Crataegus [9]. Secondly, reduction of Pseudocydonia to Chaenomeles was done by $\mathrm{Gu}$ and Spongberg [60], and their treatment is supported by Campbell et al. [7]. However, their close relationship does not receive high support in this study $(\mathrm{BP}=52, \mathrm{PP}=1)$. They have diverged for some time because the clade does not show remarkable branch length. They had better be considered distinct genera. Thirdly, Stranvaesia is morphologically similar to both Photinia and Cotoneaster and sometimes submerged into Photinia [61]. Phylogeny based on chloroplast regions done by Campbell et al. [7] indicated a close relationship between Stranvaesia and Pyracantha. However, our data support a close relationship between Stranvaesia and Cotoneaster, a relationship also supported by GBSSI-1B [7]. Fourthly, although very close morphological and genetic relationships have been revealed in almost all studies involving Eriobotrya and Rhaphiolepis, there has been no suggestion yet to merge them into one, despite the existence of their hybrids [62]. Genetic divergence between them is very recently because their clade has a relatively long branch.

4.3.2. Sorbus-Related Genera. So far, no well-sampled phylogeny of all Sorbus-related taxa is available, owing to the genetic complexity of the group and difficulties in sampling. There are ca. 250 species belonging to mainly temperate areas in the Northern Hemisphere [21], and six narrowly defined genera or subgenera under Sorbus in the broadest sense are usually accepted: Aria, Chamaemespilus, Cormus, Micromeles, Sorbus, and Torminalis [21, 37-39, 43, 58, 63-72]. These taxa fall into two clades in this study (Figure 1). Sorbus sensu stricto and Cormus with compound leaves nested in Clade I, and Aria, Chamaemespilus, and Torminalis with lobed or unlobed simple leaves nested in Clade III. Micromeles, a genus created to contain the species without persistent calyx lobes, is not a natural entity and is, therefore, unacceptable [8]. Micromeles folgneri in this study is a synonym of Sorbus folgneri. Although Cormus had been considered a synonym of Sorbus, its taxonomic position remains to be determined. Aria, Chamaemespilus, and Torminalis in Clade III are closely related and they had better merge into one separate from Sorbus.

Sorbus-related entities are notorious in taxonomy due to complexity in phenotypes resulting from interspecific hybridization and facultative agamospermy [39, 69, 70]. Apomictic microspecies confound systematic resolution of agamic complexes using nuclear markers [71]. Phylogenies based on nuclear genes may suffer from paralogue problems and chloroplast markers would work better at the very beginning when no clear ideas are available for classification.

4.3.3. Photinia-Related Genera. Four genera in their narrowest sense, Aronia, Heteromeles, Pourthiaea, and Stranvaesia, are considered related to Photinia [24, 25, 29, 31, 37]. This study demonstrates that all the five genera are superficially similar but actually distinct groups. Heteromeles possesses a soft pyrene, while Photinia possesses a soft core $[16,37,58]$. Stranvaesia is distinguishable from Photinia by the dehiscent fruits at maturity. Although Guo et al. [73] stated with quite certainty that Stranvaesia must be merged into Photinia, we believe that further studies are needed for a reliable conclusion. Pourthiaea belongs to Clade III instead of Clade II as other genera. It is readily separable from other genera by characters such as deciduous habit, warty peduncles and pedicels, and a pulp structure in the fruits [41]. The distinction of Pourthiaea is further supported by leaf epidermis and wood anatomy [74, 75]. Aronia is not a sister group of Pourthiaea because the clade is poorly supported, a conclusion that is similar to the earlier studies $([8,9,73])$.

4.3.4. Malus-Related Genera. The four genera, Docynia, Docyniopsis, Eriolobus, and Malus, really have very close relationships among them, especially between Docyniopsis and Malus. Some species have been transferred among the four genera by different authors. The monophyly of a clade comprising the four genera is indicated by our chloroplast data (Figure 1(B)). There are only two species in Docynia, two species in Docyniopsis, and one species in Eriolobus. Considering that these species are nested within Malus [18], these genera could better be merged with Malus.

\section{Conclusions}

This molecular phylogenetic study was conducted on all the genera of Maleae, by using 15 variable chloroplast gene regions. Four major clades are well resolved and the branches are well supported. These clades could be classified into four subtribes. The first radiation event gave birth to Lindleya + Kageneckia, Vauquelinia, and the ancestor of the core Maleae, and the second radiation event triggered the divergence of the genera in the core Maleae within a short time period. Within the core Maleae the four Malus-related genera should better be merged into one genus; the six Sorbus-related genera would be better classified into at least two genera; and all Photinia-related genera should be accepted as distinct genera. For a more reliable classification, phylogeny based on the whole chloroplast genomes of representative species from each genus should be used. Such a strategy has been practiced on many seed plants (e.g., [76-83]). Besides, the nuclear genes, especially the single copy nuclear genes in diploid species such as starch-branching enzyme (Sbe; [84]), should be considered with priority to document the origins of Maleae, as the maternally transmitted markers can only tell one aspect of the whole story. Application of nuclear genome information in phylogenetic reconstruction of Maleae also seems feasible, because the genomes of several species in the tribe have been sequenced, and the resequencing of many species is underway. We are expecting a completely resolved phylogeny of Maleae, and that is why we do not provide a formal taxonomic treatment in this study.

\section{Conflicts of Interest}

The authors declare that there are no conflicts of interest regarding the publication of this paper. 


\section{Supplementary Materials}

Supplementary Table S1: sequences downloaded from GenBank in this study with accession numbers. Supplementary Table S2: newly generated sequences with GenBank accession numbers in this study. (Supplementary Material)

\section{References}

[1] M. J. M. Christenhusz and J. W. Byng, "The number of known plants species in the world and its annual increase," Phytotaxa, vol. 261, no. 3, pp. 201-217, 2016.

[2] D. R. Morgan, D. E. Soltis, and K. R. Robertson, "Systematic and evolutionary implications of RBCL sequence variation in Rosaceae," American Journal of Botany, vol. 81, no. 7, pp. 890903, 1994.

[3] D. Potter, F. Gao, P. E. Bortiri, S.-H. Oh, and S. Baggett, "Phylogenetic relationships in Rosaceae inferred from chloroplast mat $\mathrm{K}$ and trn L-trn F nucleotide sequence data," Plant Systematics and Evolution, vol. 231, no. 1-4, pp. 77-89, 2002.

[4] D. Potter, T. Eriksson, R. C. Evans et al., "Phylogeny and classification of Rosaceae," Plant Systematics and Evolution, vol. 266, no. 1-2, pp. 5-43, 2007.

[5] Y. Xiang, C. Huang, Y. Hu et al., "Evolution of Rosaceae Fruit Types Based on Nuclear Phylogeny in the Context of Geological Times and Genome Duplication," Molecular Biology and Evolution, 2016.

[6] R. C. Evans and C. S. Campbell, "The origin of the apple subfamily (Maloideae; Rosaceae) is clarified by DNA sequence data from duplicated GBSSI genes," American Journal of Botany, vol. 89, no. 9, pp. 1478-1484, 2002.

[7] C. S. Campbell, R. C. Evans, D. R. Morgan, T. A. Dickinson, and M. P. Arsenault, "Phylogeny of subtribe Pyrinae (formerly the Maloideae, Rosaceae): Limited resolution of a complex evolutionary history," Plant Systematics and Evolution, vol. 266, no. 1-2, pp. 119-145, 2007.

[8] Q.-Y. Li, W. Guo, W.-B. Liao, J. A. Macklin, and J.-H. Li, "Generic limits of Pyrinae: Insights from nuclear ribosomal DNA sequences," Botanical Studies, vol. 53, no. 1, pp. 151-164, 2012.

[9] E. Y. Y. Lo and M. J. Donoghue, "Expanded phylogenetic and dating analyses of the apples and their relatives (Pyreae, Rosaceae)," Molecular Phylogenetics and Evolution, vol. 63, no. 2, pp. 230-243, 2012.

[10] G. K. Schulze-Menz, "Rosaceae," in Engler's Syllabus der Pflanzenfamilien, H. Melchior, Ed., vol. II, pp. 209-218, Gebrüder Borntraeger, Berlin, 1964.

[11] P. Goldblatt, "Cytotaxonomic Studies in the tribe quillajeae (rosaceae)," Annals of the Missouri Botanical Garden, vol. 63, no. 1, pp. 200-206, 1976.

[12] R. C. Evans, L. A. Alice, C. S. Campbell, E. A. Kellogg, and T. A. Dickinson, "The granule-bound starch synthase (GBSSI) gene in the Rosaceae: Multiple loci and phylogenetic utility," Molecular Phylogenetics and Evolution, vol. 17, no. 3, pp. 388-400, 2000.

[13] R. C. Evans and T. A. Dickinson, "Floral ontogeny and morphology in Gillenia ("Spiraeoideae") and subfamily Maloideae c. weber (Rosaceae)," International Journal of Plant Sciences, vol. 166, no. 3, pp. 427-447, 2005.

[14] E. Chevreau, Y. Lespinasse, and M. Gallet, "Inheritance of pollen enzymes and polyploid origin of apple (Malus $\mathrm{x}$ domestica Borkh.)," Theoretical and Applied Genetics, vol. 71, no. 2, pp. 268-277, 1985.
[15] N. F. Weeden and R. C. Lamb, "Genetics and linkage analysis of 19 isozyme loci in Apple," Journal of the American Society for Horticultural Science, vol. 112, pp. 865-872, 1987.

[16] J. B. Phipps, K. R. Robertson, J. R. Rohrer, and P. G. Smith, "Origins and Evolution of Subfam. Maloideae (Rosaceae)," Systematic Botany, vol. 16, no. 2, p. 303, 1991.

[17] O. Raspe, A.-L. Jacquemart, and J. De Sloover, "Isozymes in Sorbus aucuparia (Rosaceae: Maloideae): Genetic analysis and evolutionary significance of zymograms," International Journal of Plant Sciences, vol. 159, no. 4, pp. 627-636, 1998.

[18] R. Velasco, A. Zharkikh, and J. Affourtit, "The genome of the domesticated apple (Malus $\times$ domestica Borkh.)," Nature Genetics, vol. 42, no. 10, pp. 833-839, 2010.

[19] M. J. Considine, Y. Wan, M. F. D’Antuono et al., "Molecular genetic features of polyploidization and aneuploidization reveal unique patterns for genome duplication in diploid Malus," PLoS ONE, vol. 7, no. 1, Article ID e29449, 2012.

[20] J. Hutchinson, The Genera of Flowering Plants, vol. 1, Clarendon Press, UK, 1964.

[21] J. B. Phipps, K. R. Robertson, P. G. Smith, and J. R. Rohrer, "A checklist of the subfamily Maloideae (Rosaceae)," Botany, vol. 68, no. 10, pp. 2209-2269, 1990.

[22] C. Kalkman, "Rosaceae," in The Families and Genera of Vascular Plants, K. Kubitzki, Ed., pp. 343-386, Springer, Berlin, 2004.

[23] C. Linnaeus, Species Plantarum, Stockholm, Sweden, 1753.

[24] J. Lindley, "XI. Observations on the natural Group of Plants called Pomaceae," Transactions of the Linnean Society of London, vol. 13, no. 1, pp. 88-106, 1821.

[25] A. P. De Candolle, "Rosaceae," in Prodromus Systematais Naturalis Regni Vegetabilis, vol. 2, pp. 525-639, Treuttel \& Würtz, Paris, 1825.

[26] J. Lindley, "Photinia arguta," Botanical Register, vol. 23, 1956.

[27] M. J. Roemer, "Rosiflorae. Amygdalacearum et Pomacearum," in Familiarum Naturalium Regni Vegetabilis Synopses Monographicae, Weimar: Landes-Industrie-Comptoir, 1847.

[28] M. J. Decaisne, "Mémoirs sur le famile des Pomacées," Nouvelles Archives du Muséum d'Histoire Naturelle, vol. 10, pp. 113-192, 1874.

[29] T. Wenzig, "Die Pomaceen," in Charaktere der Gattungen und Arten, vol. 2, pp. 287-307, Jahrbuch des Königl Botanischen Gartens, Berlin, 1883.

[30] W. O. Focke, "Rosaceae," in Die Natürlichen Pflanzenfamilien, A. Engler and K. Prantl, Eds., vol. 3 of Engelmann, pp.1-61, Leipzig, Germany, 1894.

[31] E. Koehne, "Die Gattugngen der Pomaceen," Gartenflora, vol. 40 , p. $61,1891$.

[32] K. Fritsch, "Zur Systematik der Gattung Sorbus," Plant Systematics and Evolution, vol. 48, no. 2, p. 1-4, 47-49, 167-171., 1898.

[33] K. Fritsch, "Zur Systematik der Gattung Sorbus," Plant Systematics and Evolution, vol. 49, no. 12, 381-385, 426-429. pages, 1899.

[34] A. Rehder, Manual of Cultivated Trees and Shrubs Hardy in North America Exclusive of the Subtropical and Warmer temperate Regions, MacMillan, NY, USA, 2nd edition, 1940.

[35] A. Rehder, Bibliography of cultivated trees and shrubs hardy in the cooler temperate regions of the Northern Hemisphere, Harvard Univ., 1949.

[36] C. S. Campbell and T. A. Dickinson, "Apomixis, Patterns of Morphological Variation, and Species Concepts in subfam. Maloideae (Rosaceae)," Systematic Botany, vol. 15, no. 1, pp. 124$135,1990$. 
[37] K. R. Robertson, J. B. Phipps, J. R. Rohrer, and P. G. Smith, "A Synopsis of Genera in Maloideae (Rosaceae)," Systematic Botany, vol. 16, no. 2, p. 376, 1991.

[38] T. T. Yü, "Rosaceae (1) Spiraeoideae-Maloideae," in Flora Reipublicae Popularis Sinicae, T. T. Yü, Ed., vol. 36, Science Press, Beijing, China, 1974.

[39] J. J. Aldasoro, C. Aedo, C. Navarro, and F. M. Garmendia, “The genus sorbus (maloideae, rosaceae) in Europe and in North Africa: Morphological analysis and systematics," Systematic Botany, vol. 23, no. 2, pp. 189-212, 1998.

[40] C. Kalkman, "The Malesian species of the subfamily Maloideae Rosaceae," Blumea, vol. 21, pp. 413-442, 1973.

[41] H. Iketani and H. Ohashi, "Pourthiaea (Rosaceae) distinct from Photinia," Journal of Japanese Botany, vol. 66, pp. 352-355, 1991.

[42] R. C. Evans and T. A. Dickinson, "Floral ontogeny and morphology in subfamily Spiraeoideae endl. (Rosaceae)," International Journal of Plant Sciences, vol. 160, no. 5, pp. 981-1012, 1999.

[43] C. S. Campbell, M. J. Donoghue, B. G. Baldwin, and M. F. Wojciechowski, "Phylogenetic relationships in Maloideae (Rosaceae): Evidence from sequences of the internal transcribed spacers of nuclear ribosomal DNA and its congruence with morphology," American Journal of Botany, vol. 82, no. 7, pp. 903-918, 1995.

[44] L. Jinlu, W. Shuo, Y. Jing, W. Ling, and Z. Shiliang, "A Modified CTAB Protocol for Plant DNA Extraction," Chinese Bulletin of Botany, vol. 48, no. 1, pp. 72-78, 2013.

[45] W. Dong, C. Xu, T. Cheng, K. Lin, and S. Zhou, "Sequencing angiosperm plastid genomes made easy: A complete set of universal primers and a case study on the phylogeny of saxifragales," Genome Biology and Evolution, vol. 5, no. 5, pp. 989-997, 2013.

[46] W. Dong, C. Xu, C. Li et al., "ycf1, the most promising plastid DNA barcode of land plants," Scientific Reports, vol. 5, p. 8348, 2015.

[47] J. D. Thompson, T. J. Gibson, F. Plewniak, F. Jeanmougin, and D. G. Higgins, "The CLUSTAL X windows interface: flexible strategies for multiple sequence alignment aided by quality analysis tools," Nucleic Acids Research, vol. 25, no. 24, pp. 48764882, 1997.

[48] M. A. Larkin, G. Blackshields, N. P. Brown et al., "Clustal W and clustal X version 2.0," Bioinformatics, vol. 23, no. 21, pp. 29472948, 2007.

[49] A. Rambaut, "Se-Al: Sequence alignment editor. ver. 2.0," Available from http://tree.bio.ed.ac.uk/software/seal/, 1996.

[50] P. Librado and J. Rozas, "DnaSP v5: a software for comprehensive analysis of DNA polymorphism data," Bioinformatics, vol. 25, no. 11, pp. 1451-1452, 2009.

[51] D. L. Swofford, PAUP*: Phylogenetic Analysis Using Parsimony (and Other Methods), Sinauer Associates, Sunderland, Version 4.0b10 edition, 2003.

[52] G. Vaidya, D. J. Lohman, and R. Meier, "SequenceMatrix: Concatenation software for the fast assembly of multi-gene datasets with character set and codon information," Cladistics, vol. 27, no. 2, pp. 171-180, 2011.

[53] A. Stamatakis, "RAxML version 8: a tool for phylogenetic analysis and post-analysis of large phylogenies," Bioinformatics, vol. 30, no. 9, pp. 1312-1313, 2014.

[54] F. Ronquist and J. P. Huelsenbeck, "MrBayes 3: bayesian phylogenetic inference under mixed models," Bioinformatics, vol. 19, no. 12, pp. 1572-1574, 2003.
[55] D. Posada and K. A. Crandall, "MODELTEST: testing the model of DNA substitution," Bioinformatics, vol. 14, no. 9, pp. 817-818, 1998.

[56] W. Dong, J. Liu, J. Yu, L. Wang, S. Zhou, and A. Moustafa, "Highly Variable Chloroplast Markers for Evaluating Plant Phylogeny at Low Taxonomic Levels and for DNA Barcoding," PLoS ONE, vol. 7, no. 4, p. e35071, 2012.

[57] P. Leins, The Carpel in Superior and Inferior Gynoecia, vol. 85 of Berichteder Deutschen Botanischen Gesellschaft, 1972.

[58] J. R. Rohrer, K. R. Robertson, and J. B. Phipps, "Floral morphology of Maloideae (Rosaceae) and its systematic relevance," American Journal of Botany, vol. 81, no. 5, pp. 574-581, 1994.

[59] W. B. Zomlefer, Guide to Flowering Plant Families, Chapel Hill: University of North Carolina Press, 1994.

[60] C. Gu and S. Spongberg, "Chaenomeles," in Flora of China, Z. $\mathrm{Wu}$ and P. Raven, Eds., pp. 46-434, Science Press, Beijing, China, Missouri Botanical Garden Press, St. Louis, Missouri, USA, 2003.

[61] J. E. Vidal, "Notes sur quelques Rosacées Asiatique (II) (Photinia Stranvaesia)," Adansonia, vol. 5, pp. 221-237, 1965.

[62] J. J. Aldasoro, C. Aedo, and C. Navarro, "Phylogenetic and phytogeographical relationships in maloideae (Rosaceae) based on morphological and anatomical characters," Blumea: Journal of Plant Taxonomy and Plant Geography, vol. 50, no. 1, pp. 3-32, 2005.

[63] T. Hedlund, "Monographie der Gattung Sorbus," Königl Svenska Vetenskaps-Akademiens Handlingar, vol. 35, pp. 1-147, 1901.

[64] A. Rehder, "Sorbus L," in Plantae Wilsonianae, C. S. Sargent, Ed., vol. 2, pp. 266-279, Cambridge University Press, Cambridge, NY, USA, 1915.

[65] M. Kovanda, “Taxonomical studies in Sorbus subg. Aria," Dendrologicky Sborník, vol. 3, pp. 23-70, 1961.

[66] J. E. Vidal, "Sorbus L," in Flore du Cambodge, du Laos and du Vietnam, Eds., vol. 6, pp. 23-34, Museum National d'Histoire Naturelle, 1968.

[67] E. Gabrielian, "The Genus Sorbus L," in Eastern Asia and the Himalayas, Armenian Academy of Sciences, Yerevan, Armenia, 1978.

[68] M. Kovanda and J. Challice, "The genus Micromeles revisited," Folia Geobotanica et Phytotaxonomica, vol. 16, no. 2, pp. 181-193, 1981.

[69] A. Jankun, "Evolutionary significance of apomixis in the genus Sorbus Rosaceae," Fragmenta Floristica et Geobotanica, vol. 38, no. 2, pp. 627-686, 1993.

[70] G. Aas, J. Maier, M. Baltisberger, and S. Metzger, "Morphology, isozyme variation, cytology, and reproduction of hybrids between Sorbus aria (L.) Crantz and S.torminalis (L.) Crantz," Botanica Helvetica, vol. 104, no. 2, pp. 195-214, 1994.

[71] C. S. Campbell, W. A. Wright, T. F. Vining, and W. A. Haltemen, "Morphological variation in sexual and agamospermous Amelanchier (Rosaceae)," Canadian Journal of Botany, vol. 75, no. 7, pp. 1166-1173, 1997.

[72] J. J. Aldasoro, C. Aedo, F. M. Garmendia, F. P. Hoz, and C. Navarro, "Revision of Sorbus Subgenera Aria and Torminaria (Rosaceae-Maloideae)," Systematic Botany Monographs, vol. 69, pp. 1-148, 2004.

[73] W. Guo, Y. Yu, R.-J. Shen, W.-B. Liao, S.-W. Chin, and D. Potter, "A phylogeny of Photinia sensu lato (Rosaceae) and related genera based on nrITS and cpDNA analysis," Plant Systematics and Evolution, vol. 291, no. 1, pp. 91-102, 2011. 
[74] L. T. Lu, Z. L. Wang, and G. Li, “The significance of the leaf epidermis in the taxonomy of the Photinia complex (Rosaceae Maloideae)," Cathaya, vol. 3, pp. 93-108, 1991.

[75] S. Zhang and P. Baas, "Wood anatomy of trees and shrubs from china. III. rosaceae," IAWA Journal, vol. 13, no. 1, pp. 21-91, 1992.

[76] R. C. Haberle, Phylogeny and Comparative Chloroplast Genomics of the Campanulaceae [Ph.D. thesis], Austin, University of Texas, 2006.

[77] E. Bortiri, D. Coleman-Derr, G. R. Lazo, O. D. Anderson, and Y. Q. Gu, "The complete chloroplast genome sequence of Brachypodium distachyon: sequence comparison and phylogenetic analysis of eight grass plastomes," BMC Research Notes, vol. 1, article 61, 2008.

[78] M. Parks, R. Cronn, and A. Liston, "Increasing phylogenetic resolution at low taxonomic levels using massively parallel sequencing of chloroplast genomes," BMC Biology, vol. 7, article no. 84, 2009.

[79] J.-H. Xue, W.-P. Dong, T. Cheng, and S.-L. Zhou, "Nelumbonaceae: Systematic position and species diversification revealed by the complete chloroplast genome," Journal of Systematics and Evolution, vol. 50, no. 6, pp. 477-487, 2012.

[80] S. V. Nikiforova, D. Cavalieri, R. Velasco, and V. Goremykin, "Phylogenetic analysis of 47 chloroplast genomes clarifies the contribution of wild species to the domesticated apple maternal line," Molecular Biology and Evolution, vol. 30, no. 8, pp. 17511760, 2013.

[81] J. L. Cotton, W. P. Wysocki, L. G. Clark et al., "Resolving deep relationships of PACMAD grasses: A phylogenomic approach," BMC Plant Biology, vol. 15, no. 1, article no. 178, 2015.

[82] T. G. Ross, C. F. Barrett, M. Soto Gomez et al., "Plastid phylogenomics and molecular evolution of Alismatales," Cladistics, vol. 32, no. 2, pp. 160-178, 2016.

[83] Y. Sun, M. J. Moore, S. Zhang et al., "Phylogenomic and structural analyses of 18 complete plastomes across nearly all families of early-diverging eudicots, including an angiospermwide analysis of IR gene content evolution," Molecular Phylogenetics and Evolution, vol. 96, pp. 93-101, 2016.

[84] Y. Han, K. Gasic, F. Sun, M. Xu, and S. S. Korban, "A gene encoding starch branching enzyme I (SBEI) in apple (Malus $\times$ domestica, Rosaceae) and its phylogenetic relationship to Sbe genes from other angiosperms," Molecular Phylogenetics and Evolution, vol. 43, no. 3, pp. 852-863, 2007.

[85] B. Oxelman, M. Lidén, and D. Berglund, "Chloroplast rps16 intron phylogeny of the tribe Sileneae (Caryophyllaceae)," Plant Systematics and Evolution, vol. 206, no. 1-4, pp. 393-410, 1997. 


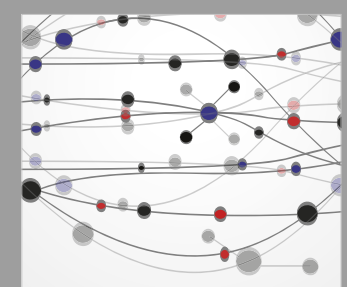

The Scientific World Journal
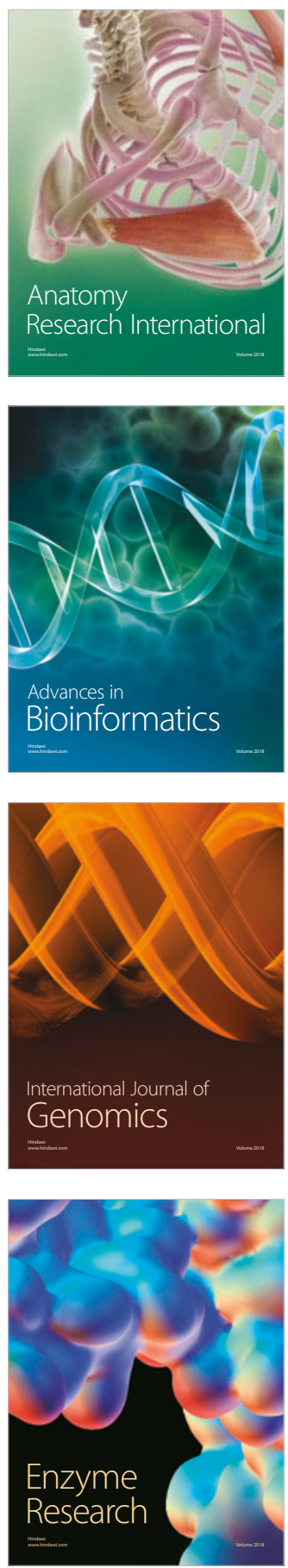
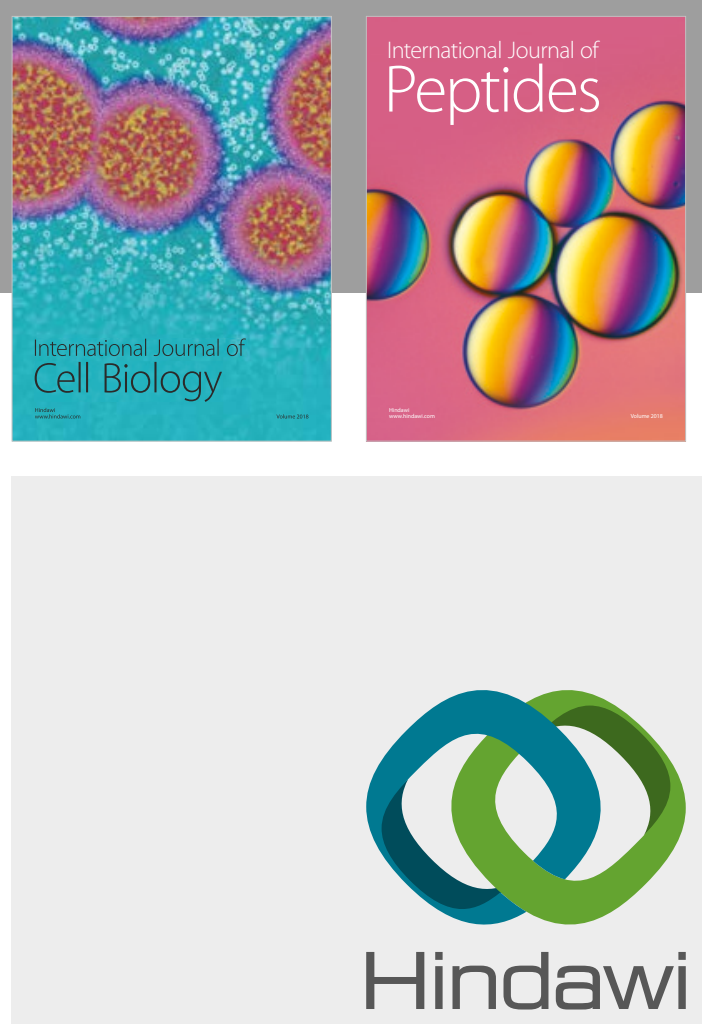

Submit your manuscripts at

www.hindawi.com
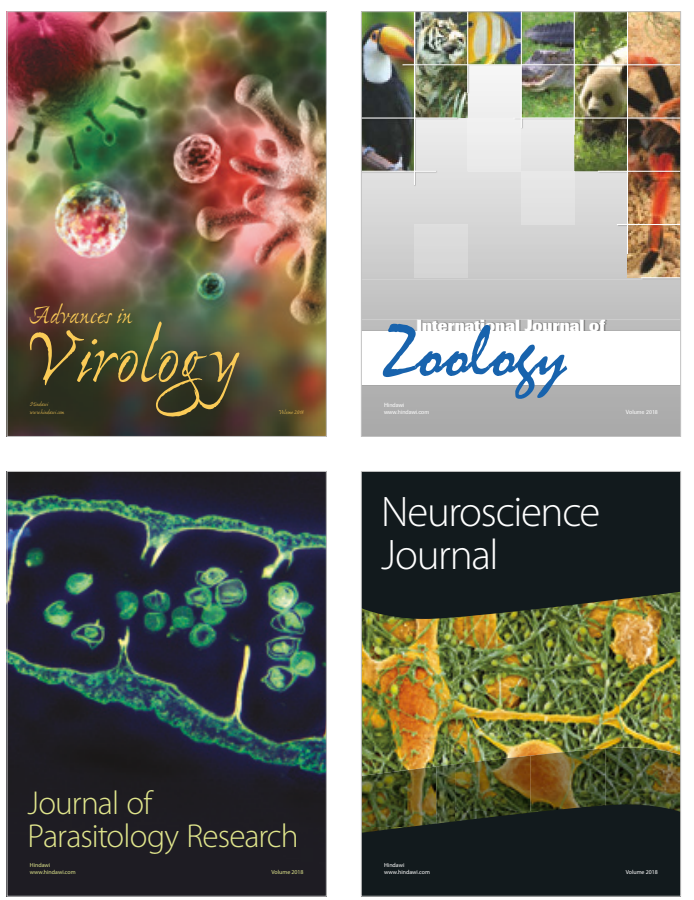
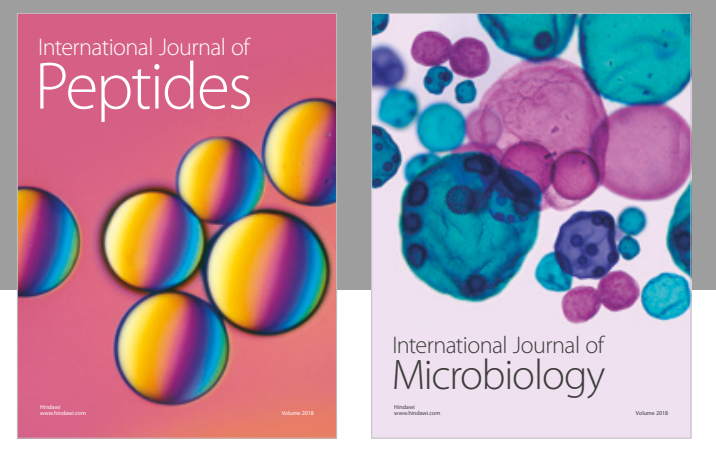

nternational Journal of Microbiology
Journal of
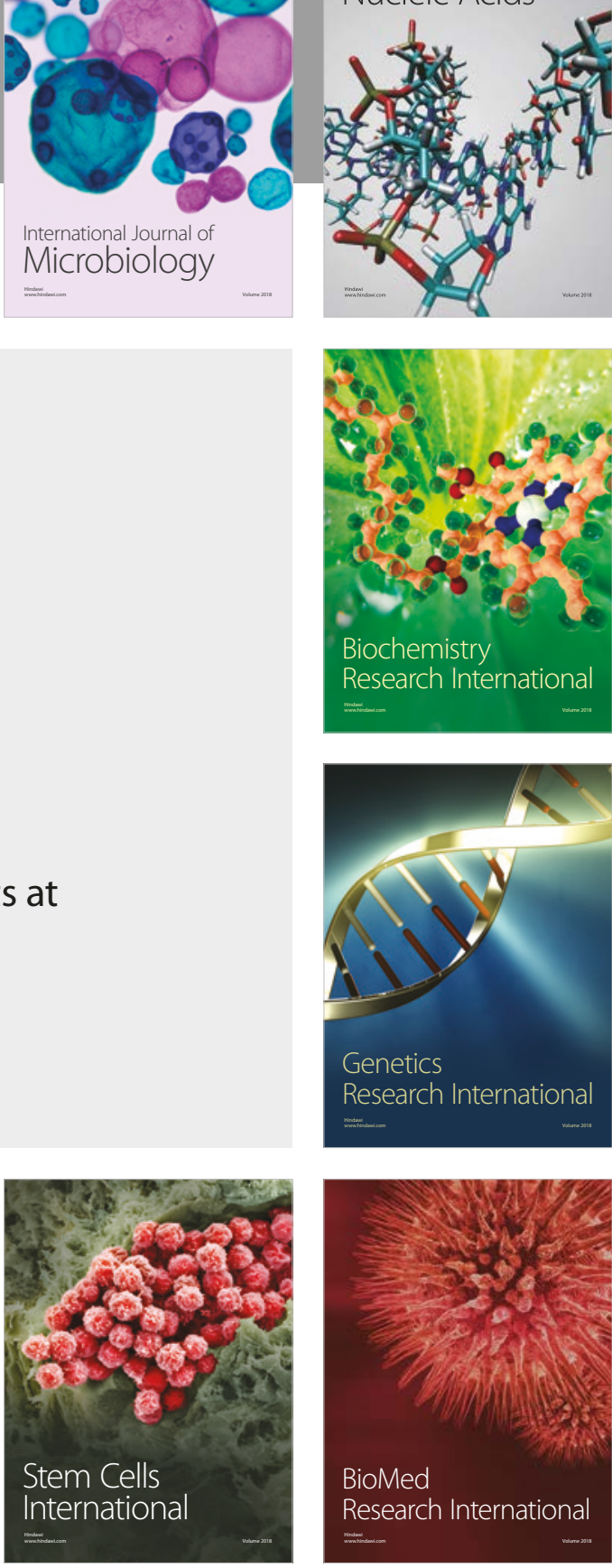
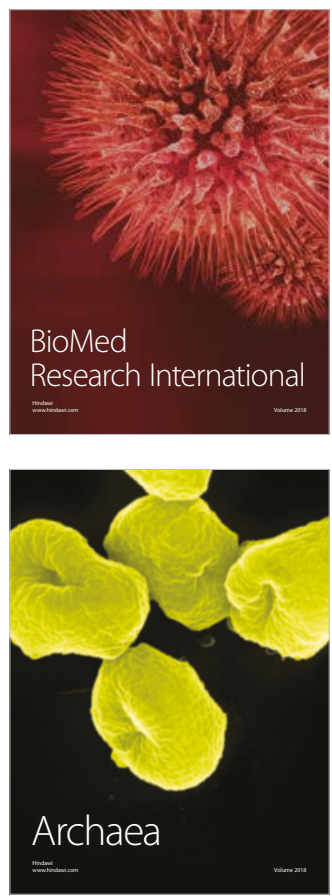